\title{
Fernando Pessoa leitor de Novalis e o problema da heteronímia
}

\author{
Nuno Ribeiro*
}

\section{Resumo}

\begin{abstract}
O presente artigo pretende averiguar as relações entre as leituras que Pessoa fez da obra de Novalis, o escritor e pensador alemão, e a problemática da heteronímia. Com efeito, na Biblioteca Particular de Fernando Pessoa existem inúmeras referências às obras de Novalis. Para além de manuais com alusões ao pensamento desse autor alemão, encontramos ainda, na Biblioteca de Fernando Pessoa, uma tradução francesa de obras de Novalis que reúne Os discípulos em Saïs seguidos de uma selecção de Os fragmentos. Esta tradução francesa do livro de Novalis, que foi sublinhada e anotada por Pessoa, está na origem de inúmeras referências presentes tanto nos escritos publicados em vida por Fernando Pessoa, quanto naqueles que se encontram no seu espólio. Entre esses escritos impulsionados pela leitura de Novalis encontram-se os textos sobre a heteronímia. Assim, partindo de uma periodização e análise da leitura pessoana de Novalis, pretende elucidar-se até que ponto a leitura de Novalis poderá estar na origem das reflexões teóricas de Pessoa sobre a criação dos seus heterónimos.
\end{abstract}

Palavras-chave: Fernando Pessoa. Novalis. Heteronímia. Biblioteca. Particular de Pessoa. Espólio de Pessoa.

\section{Vestígios da leitura pessoana de Novalis}

O interesse de Fernando Pessoa pela obra de Novalis é um facto suficientemente comprovado pelos livros presentes na Biblioteca Particular de Pessoa. Na Biblioteca de Pessoa, conservada na Casa Fernando Pessoa, encontramos uma tradução em francês de obras de Novalis - sublinhada e anotada por Pessoa - que reúne Os discípulos em Saïs [Les disciples a Saïs] seguidos de uma selecção de Os fragmentos [Les fragments] [CFP, 8-388]. ${ }^{1}$ Esta tradução e o prefácio que a antecede são da autoria de Maurice Maeterlinck, o dramaturgo francês que viria a influenciar a

1 A referência completa do livro é: Friedrich Novalis, Les disciples a Saïs et Les fragments de Novalis (traduits de l'allemand et precécédés d'une introduction par Maurice Maeterlinck), Bruxelles, Paul Lacomblez, 1914. [CFP, 8-388].

* Universidade de Lisboa 
produção teatral de Fernando Pessoa. Para além desta tradução de obras de Novalis, existe ainda na Biblioteca Particular de Pessoa um livro da autoria de Henri Lichtenberger intitulado Novalis [CFP, 8-169], ${ }^{2}$ que contém uma análise e exposição detalhadas da vida e obra do autor alemão. No entanto, a leitura pessoana relativa a Novalis viria a ter lugar no âmbito de um interesse mais vasto da parte de Fernando Pessoa: o interesse pela literatura alemã. Um testemunho desse interesse mais vasto pela literatura alemã é o livro The literature of Germany [CFP, 8-470] da autoria de J. G. Robertson, ${ }^{3}$ que se encontra sublinhado por Pessoa e inclui uma descrição da evolução da literatura germânica desde a época medieval até ao pós-romantismo. No capítulo "V" desse livro, intitulado "Romantismo" ["Romanticism" - CFP, 8-470: pp. 144 - 187], encontramos, no contexto da caracterização do primeiro romantismo alemão, referências a Novalis. Aí lemos, na sequência da enunciação dos autores da primeira escola do romantismo alemão, a seguinte alusão a Novalis:

(...) o mais inspirado de todos, Friedrich von Hardenberg, conhecido como Friedrich Novalis, o poeta da Escola, que morreu de exaustão com vinte e nove anos de idade.

[(...) most inspired of all, Friedrich von Hardenberg, known as Friedrich Novalis, the poet of the School, who died of consumption at the age of twenty-nine.]

[CFP, 8-470: p.147]

Esta alusão sumária a Novalis, que aparece no seguimento da enumeração de Ludwig Tieck, Friedrich Schlegel e August Wilhelm Schlegel, caracteriza-o como o mais inspirado de entre os autores pertencentes à escola do primeiro romantismo. ${ }^{4}$ Esta indicação relativa a Novalis terá sido

2 A referência do livro é: Henri Lichtenberger, Novalis, Paris, Bloud \& C $C^{\text {ie }}$ Éditeurs, 1912. [CFP, 8-169].

3 O livro tem a seguinte referência: J. G. Robertson, The literature of Germany, London, Williams \& Northgate, 1913. [CFP, 8-470]

4 A leitura do trecho citado do livro de Robertson, publicado em 1913, terá estado na origem de uma observação crítica relativa ao primeiro romantismo presente num fragmento dactiloscrito atribuído a António Mora, uma personalidade literária de Fernando Pessoa, onde se lê: "Com o romantismo allemão, propriamente dito, o dos Schlegel, de Tieck e de Novalis, entra a litteratura germanica em decadencia, referindo-nos, por comparação, á precedente literatura de Schiller e de Goethe, se bem que o primeiro pecasse (houvesse pecado) na sua utilisação do que admirava no paganismo." (BNP/ E3, $12^{1}-71^{\text {r: }}$ Cf, PESSOA, 2002, p. 282). Com efeito, neste trecho, que foi redigido posteriormente ao início de Março de 1914, encontramos a enumeração dos nomes que são mencionados no capítulo "Romanticism" do livro The literature of Germany. No verso do documento que contém este trecho encontramos uma carta dactilografada da empresa "Lavado, Pinto \& Companhia" - para a qual Pessoa trabalhou - com a data de "9 de Março de 1914". Pessoa terá aproveitado, em momento 
um dos indícios que terão incitado Pessoa à leitura de obras de e sobre este autor alemão.

Um indício da leitura pessoana de Novalis encontra-se desde logo presente num texto publicado por Pessoa no decurso da sua vida. Esse texto é "O provincianismo português", publicado a 12 de Agosto de 1928, no jornal O Notícias Ilustrado. No final de "O provincianismo português" lemos o seguinte: "Estamos perto de acordar, disse Novalis, quando sonhamos que sonhamos." (PESSOA, 2000, p. 373). Esta referência corresponde a um fragmento que se encontra sublinhado por Pessoa na tradução francesa de Novalis presente na sua Biblioteca Particular. Com efeito, lemos na tradução de Novalis presente na Biblioteca de Fernando Pessoa:

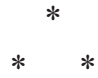

Estamos perto de acordar quando sonhamos que sonhamos.

$*$

[Nous sommes prés du réveil quand nous rêvons que nous rêvons.]

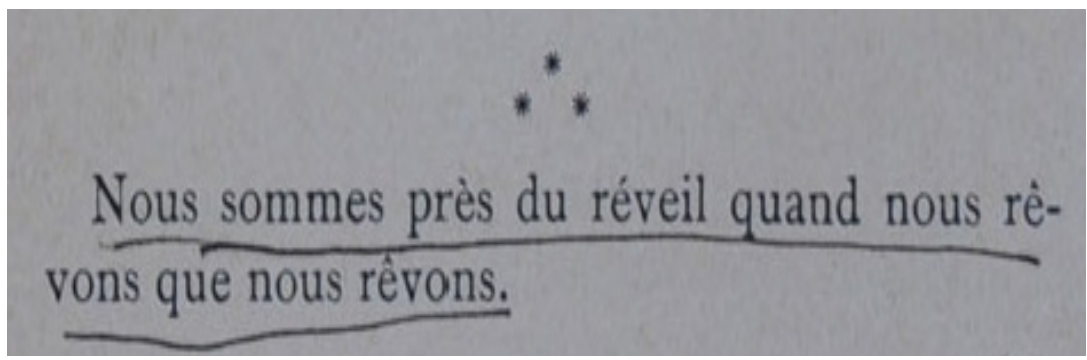

[CFP, 8-388: p.77: detalhe do fac-simile $]^{5}$

aproximado embora posterior a essa data, o verso da carta (que constitui o "rosto" do documento catalogado Biblioteca Nacional) para redigir esse texto destinado a Mora. O facto de o documento ser datado de Março de 1914, data aproximada da redacção do texto, conjugado com a circunstância de o livro The literature of Germany de Robertson ter sido publicado em 1913 permite-nos concluir que a leitura deste livro de Robertson, que está origem do trecho do texto de Mora, terá ocorrido entre 1913 e o início de 1914. No fragmento de Mora, o nome de Novalis assim como dos restantes autores do primeiro romantismo alemão são referidos como sintoma de decadência face às obras de Goethe e de Schiller. No entanto, a avaliação feita neste fragmento aparece no contexto da reconstrução do paganismo e portanto da crítica ao romantismo como distanciamento do espírito que animava o paganismo. Em outros trechos da obra de Pessoa existe, como teremos a oportunidade de mostrar, uma reapropriação de Novalis, assim como de alguns nomes do romantismo, que tem um sentido inverso às considerações presentes neste trecho de António Mora.

5 Os fac-similes dos livros de Fernando Pessoa foram consultados na Biblioteca digital de Fernando Pessoa, da Casa Fernando Pessoa [CFP]. Disponível em: http://casafernandopessoa.cm- 
No entanto, as referências de Pessoa a Novalis são muito anteriores à publicação de "O provincianismo português" em 1928. No espólio de Fernando Pessoa encontra-se uma lista, datável de 1907, intitulada "Poetry" [BNP/E3, $\left.48-114^{\mathrm{r}}\right]$ que contém alguns dos mais significativos nomes da literatura, entre os quais se encontra o nome de Novalis. Com efeito, lemos nessa lista:

Poetry.

Baudelaire.

Rollinat (Maurice).

Stéphane Mallarmé. (École Symboliste.)

Regnier (Henri de) Poémes.

Gresset - "Poésies choisies". Quantin. 1883.

Nathaniel Hawthorne.

Tieck.

Novalis.

Chamisso.

La Motte-Fouqué.

Hoffman.

Victor Hugo ("Han d'Island". "Léguer des Siècles" "Rin")

Th. Gaultier. ("Spirite". "Roman de la Momie". and many tales and some poems).

Merimée (“Lokis.” "Le Venus d'Ille”.)

Nodier. ("Trilby." "Inês de las Sierras".)

Baudelaire.

Mallarmé (St.): "Pages." "Vers et Prose." "Divagations." "Poésies."

Verlaine : Euvres Complètes. 1899.

(Vanier) 


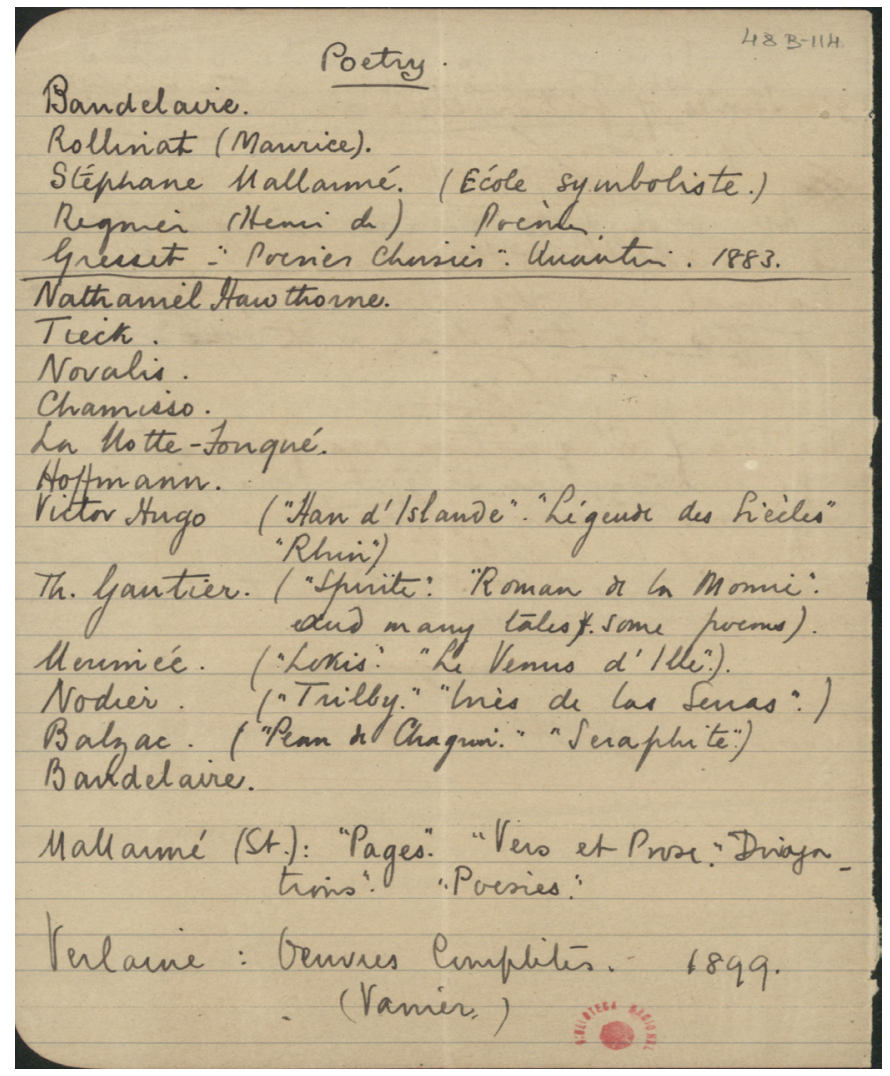

[BNP/E3, 48B - 114r: fac-simile $]^{6}$

O título "Poetry" que antecede os autores apresentados na lista refere-se muito provavelmente ao título de um ensaio sobre a poesia que Pessoa pretendia redigir cerca de $1907 .^{7}$ A lista encontra-se dividida em duas partes que são

6 Os documentos do espólio de Fernando Pessoa apresentados neste artigo foram consultados na Biblioteca Nacional de Portugal [BNP], Espólio 3 [E3].

7 Numa lista presente no espólio de Pessoa intitulada "Ensaios" ["Essays": BNP/E3, 48B - 6r] que contém obras projectadas por este autor nos anos de 1906 e 1907 encontramos a referência a um ensaio intitulado "Poesia" ["Poetry"], que aparece listado em sétimo lugar. De facto, lemos nessa lista:

Essays:

1. The Work of the Human Imagination.

2. Reasoning, and its fallacies.

3. The categories.

4. God and the world.

5. Timidity and the Timidity.

6. The Philosophy of the Catholic Church.

7. Poetry. 
separadas por uma barra divisória. Os nomes que se encontram acima da barra divisória correspondem aos autores que Pessoa pretendia considerar no ensaio intitulado "Poetry". Os autores e títulos abaixo da linha divisória correspondem a leituras diversas que Pessoa pretendia fazer, algumas das quais poderiam vir a ser incluídas no ensaio "Poetry". A referência a Novalis aparece abaixo da linha divisória e corresponde, por conseguinte, a uma dessas leituras diversas que seriam eventualmente objecto do ensaio sobre poesia. Esta circunstância mostra que Pessoa teria, já em 1907, conhecimento da obra de Novalis, muito possivelmente por via de compêndios de literatura, e testemunha a intenção pessoana de ler obras deste autor alemão. No entanto, a leitura directa de obras Novalis viria a realizar-se somente alguns anos depois com a aquisição da tradução francesa de Os discípulos em Saiis seguidos de Os fragmentos. A tradução francesa dos textos de Novalis presente na Biblioteca de Pessoa apresenta a data de publicação de 1914 e terá sido, por esse motivo, lida por Pessoa posteriormente a essa data. A circunstância de a tradução e introdução serem da autoria de Maurice Maeterlinck é um facto muito significativo.

A leitura do teatro de Maeterlinck, de que a Biblioteca de Pessoa nos apresenta vários exemplares, ${ }^{8}$ foi de fundamental importância para a constituição daquilo que Fernando Pessoa denominou de "Theatro Estático" e viria a originar múltiplos projectos para a redacção de peças de teatro, das quais o espólio de Pessoa nos fornece vários testemunhos. ${ }^{9}$ De entre as diversas peças de teatro destinadas ao

8. Percy Bysshe Shelley - Character and Work.

9. Edgar Allan Poe - Character and Work.

10. Genius - its logic and character.

11. Free-Will.

12. Phrenology.

13. Physiognomical Observations.

14. Jean-Jacques Rousseau.

15. The Logic of Graphology.

16. The Christian Religion.

17. $\square$

18. $\square$

19. $\square$

20. $\square$

[BNP/E3, 48B $\left.-6^{\mathrm{r}}\right]$

A circunstância de esta lista conter títulos de ensaios que Pessoa pretendeu redigir por volta dos anos de 1906 e 1907 leva-nos a crer que pode é datável por volta de 1907. Isto leva-nos igualmente a crer que os fragmentos preparatórios destes ensaios presentes no espólio de Pessoa, como é o caso da lista intitulada "Poetry", devam também ser datados por volta deste ano.

$8 \mathrm{Na}$ Biblioteca Particular de Pessoa encontramos as seguintes referências a obras de teatro de Maeterlinck: Maurice Maeterlinck, Théatre, 3 vols., Bruxelles, Paul Lacomblez, 1908 [CFP, 8-333]; Maurice Maeterlinck, Monna Vanna, Paris, Librairie Charpentier et Fasquelle, 1913 [CFP, 8-332].

$9 \mathrm{Na}$ edição de O marinheiro, Cláudia Souza apresenta-nos uma lista do espólio de Pessoa 
projecto do "Theatro Estático", Pessoa chegou a publicar uma peça no decurso da sua vida. Essa peça é $\mathbf{O}$ marinheiro que teve a primeira aparição pública no primeiro número da revista Orpheu em Março de 1915. O interesse de Pessoa pelo teatro de Maurice Maeterlinck conjugado com o intuito de ler obras de Novalis terão levado Fernando Pessoa a adquirir a tradução francesa de Os discípulos em Saïs seguida de Os fragmentos. O facto de essa tradução ter sido publicada em 1914 é também bastante significativo, dado ser a época que antecede a publicação de $\mathbf{O}$ marinheiro e, por consequência, um dos períodos de maior interesse de Pessoa pela obra de Maeterlinck. Assim, a conjugação de todos estes aspectos apresenta-nos as circunstâncias que conduzem Fernando Pessoa a ler Novalis na tradução francesa que se encontra presente na sua Biblioteca.

\section{Os fragmentos de Novalis e os textos sobre a heteronímia}

De entre os textos contidos na tradução francesa de Novalis feita por Maurice Maeterlinck, a secção de Os fragmentos viria a ser a parte que mais repercussão teria na produção literária de Pessoa. Com efeito, um facto que surpreende o leitor da tradução francesa dos textos de Novalis presente da Biblioteca Particular de Pessoa é a circunstância de apenas Os fragmentos apresentarem sublinhados e comentários de leitura. Nem a introdução de Maeterlinck, nem Os discípulos em Saiis apresentam quaisquer sublinhados ou notas, o que contrasta com a superabundância de indicações de leitura presentes no texto de Os fragmentos. A leitura de Os fragmentos constituiu-se, deste modo, como a base para a construção de algumas das produções teóricas e poéticas de Fernando Pessoa. Um exemplo disso é o seguinte texto:

O poder de despertar verdadeiramente em si uma individualidade estranha-(e não de simplesmente enganar por uma imitação superficial) é ainda inteiramente desconhecido e reside numa muito admirável penetração e mímica espiritual. $\mathrm{O}$ artista devém tudo aquilo que vê e que quer ser.

[Le pouvoir d'éveiller véritablement en soi une individualité étrangère - (et non de tromper simplement par une imitation superficielle) est encore entièrement inconnu et repose sur une très étonnante pénétration et mimique spirituelle. L'artiste devient tout ce qu'il voit et tout ce qu'il veut être.]

intitulada "Theatro estático" [BNP/E3, 48I - 1 $]$ que elenca sete peças de teatro classificáveis sob essa designação e que dão testemunho da influência de Maeterlinck sobre a produção literária de Pessoa. (Cf. PESSOA, 2010, p10.). 


\section{Le pouvoir d'éveiller véritablement en soi} une individualité étrangère - (et non de tromper simplement par une imitation superficielle) est encore entièrement inconnu et repose sur une très étonnante pénétration et mimique spirituelle. L'artiste devient tout ce qu'il voit et tout ce qu'il veut être.

[CFP $-8-388:$ p. $183-$ fac-simile $]$

Quem lê a afirmação final deste texto - segundo a qual "O artista devém tudo aquilo que vê e que quer ser" - não pode deixar de se lembrar da afirmação presente num trecho de um fragmento dactiloscrito do poema "A passagem das horas", de Álvaro de Campos, onde lemos:

Eu quero ser sempre aquillo com quem sympathiso,

Eu torno-me sempre, mais tarde ou mais cedo,

Aquillo com quem sympathiso, seja uma pedra ou uma ansia,

Seja uma flor ou uma idèa abstracta.

Seja uma multidão ou um modo de comprehender Deus.

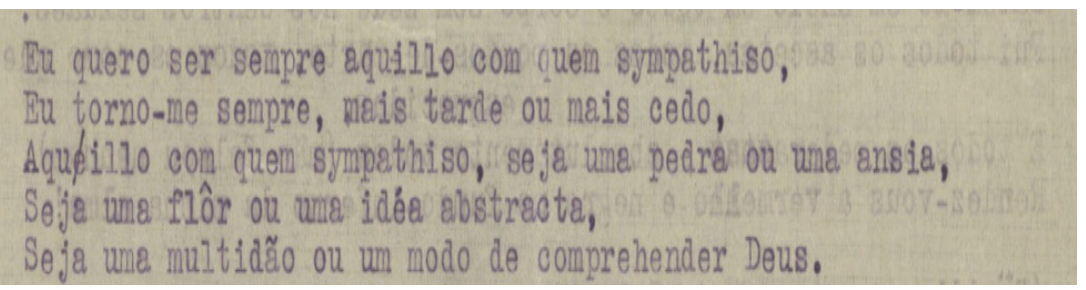

[BNP/E3, 70 -15: detalhe do fac-simile] (PESSOA, 2002a, p. 196)

Este trecho do poema de Álvaro Campos, que foi certamente impulsionado pela leitura do fragmento citado de Novalis, é datado de 22 de Maio de 1916. Esta circunstância permite-nos circunscrever de um modo mais determinado o período de leitura da tradução francesa de Novalis presente na Biblioteca de Pessoa. Tendo em conta que a tradução francesa de Novalis foi publicada em 1914 e que o trecho de "A passagem das horas" citado apresenta a data de 22 de Maio de 1916, pode concluir-se que a leitura do livro de Novalis presente 
na Biblioteca de Pessoa deverá situar-se entre 1914 e o início de 1916. No entanto, apesar de a produção poética e literária de Pessoa apresentar alguns indícios pontuais da leitura da Novalis - em especial de Os fragmentos -, o contacto com a obra do autor alemão viria a ter repercussão numa dimensão mais fundamental da produção de Fernando Pessoa. Essa dimensão diz respeito aos textos de teoria da heteronímia.

Nos textos de Pessoa sobre a teoria da heteronímia encontramos os herdeiros mais directos da leitura pessoana de Novalis. Com efeito, "o poder de despertar verdadeiramente em si uma individualidade estranha" de que nos fala Novalis é uma das condições da produção heteronímica. A teoria da despersonalização e do sentir por meio de uma outra personalidade desenvolvidos nos textos relativos à criação dos heterónimos viriam a reflectir algumas das considerações lidas e sublinhadas por Pessoa na tradução francesa de Os fragmentos de Novalis. Um exemplo claro disso é o texto "Aspectos", um dos escritos fundamentais de Pessoa relativos à heteronímia. Este texto, cujos fragmentos terão sido redigidos por volta de 1918 e, por conseguinte, em data posterior à leitura de Os fragmentos de Novalis, foi concebido por Pessoa como um prefácio para a publicação da obra de algumas das suas personalidades. Num trecho destinado ao texto "Aspectos" lemos:

A obra complexa, cujo primeiro volume é este, é de substancia dramatica, embora de forma varia - aqui de trechos em prosa, em outros livros de poesia ou de philosophias.

É, não sei se um privilegio se uma doença, a constituição mental, que a produz. O certo, porém, é que o author d'estas linhas - não sei bem se o author d'estes livros - nunca teve uma só personalidade, nem nunca pensou senão dramaticamente, isto é, numa pessoa, ou personalidade, supposta, que mais propriamente do que elle proprio pudesse ter esses sentimentos. Ha autores que escrevem dramas e novellas; e nesses dramas e nessas novellas attribuem sentimentos e idéas ás figuras, que as povoam, que muitas vezes se indignam que sejam tomados por sentimentos seus, ou idéas suas. Aqui a substancia é a mesma, embora a fórma seja diversa.

A cada personalidade mais demorada, que o author d'estes livros, conseguiu viver dentro de si, elle deu uma indole expressiva, e fez d'essa personalidade um author, com um livro, ou livros, com as idéas, as emoções, e a arte dos quaes, elle, o author real (ou porventura apparente, porque não sabemos o que seja a realidade), nada tem, salvo o ter sido, no escrevel-as, o médium de figuram que elle-proprio creou. 
A obra complexa, cujo primeiro volume é este, é de substancia dramatica, embora de forma varia aqui de trechos em prosa, em outros livros de poemas ou de philosophias.

$\mathrm{B}$, nẫo sei se um privilegio se uma doença, a constituição mentak, que a produz. 0 certo, porém, é que o author d'estas linhas - não sei bem se 0 author d'estes livros - nunca teve uma só personalidade, nem pensou nunca, nem sentiu, senão dramaticamente, isto é, numa pessoa, ou personalidade, supposta, que mais propriamente do aue elle proprio pudesse ter esses sentimentos.

Ha authores que escrevem dramas e novellas; e nesses dramas e nessas novellas attribuem sentimentos e idéas ás figuras, que as povoam, que muitas vezes se indignam que sejam tomados por sentimentos seus, ou idéas suas. Aqui a substancia é a. mesma, embora a fórma seja diversa.

A cada personalidade mais demorada, que 0 author d'estes livros, conseguiu viver dentro de si, elle deu uma indole expressiva, e fez d'essa personalidade um author, com up livro, ou livros, com as idéas, as emoções, e a arte dos quaes, elle, o author real (ou porventura apparente, porque não sabemos 0 que seja a realidade), nada tem, salvo o ter sido, no escrevel-as, o medium de figuras que elle-proprio creou.

$\left[\mathrm{BNP} / \mathrm{E} 3,20-70^{\mathrm{r}} \text { : fac-simile }\right]^{10}$

Com efeito, as considerações realizadas neste trecho destinado ao texto “Aspectos" são animadas pelo espírito do fragmento de Novalis supracitado. De acordo com os elementos presentes neste trecho, a fabricação da heteronímia pressupõe um processo de despersonalização dramática. ${ }^{11}$ Este processo de despersonalização dramática corresponde à criação daquilo que Pessoa, na Tábua Bibliográfica publicada em 1928 na revista Presença, denomina de

10 - Este texto é transcrito em apêndice à edição crítica do Livro do desassocego. (Cf.: PESSOA, 2010a, p. 449).

11 - A importância da noção de "despersonalização" para a constituição da heteronímia aparece explicitamente declarada no seguinte trecho da carta de Fernando Pessoa, sobre a génese da heteronímia, dirigida a Adolfo Casais Monteiro com a data de 13 de Janeiro de 1935: "Seja como for, a origem mental dos meus heterónimos está na minha tendência orgânica e constante para a despersonalização e para a simulação.” (PESSOA, 1999, p. 340). Essa carta, que explora muitas das questões desenvolvidas no texto "Aspectos", constitui-se igualmente como um dos escritos pessoanos fundamentais para a compreensão do processo de despersonalização dramática desenvolvido ao longo dos textos teóricos de Fernando Pessoa. 
“drama em gente". ${ }^{12}$ A constituição de um processo de despersonalização dramática, implícito no drama em gente, implica a criação de uma nova concepção de espaço literário que mantenha $a$ substância do drama mas que altere a forma da peça dramática. De acordo com um texto de Pessoa intitulado "Ensaio sobre o drama" aquilo que caracteriza especificamente a forma de uma peça dramática é o facto de as personagens, a interacção entre as diversas personagens e a fábula através da qual essa interacção ocorre se encontrarem unificadas num único texto, isto é, num todo orgânico. É isso que lemos o seguinte trecho do "Ensaio sobre o drama":

O Drama, como todo objectivo, compõe-se organicamente de três partes - das pessoas ou caracteres; da entreacção dessas pessoas; e da acção ou fábula, por meio e através da qual essa entreacção se realiza, essas pessoas se manifestam. (PESSOA, 1986a, p. 106).

A criação de um espaço literário que mantenha a substância do drama, mas que altere a forma da peça dramática pressupõe que as diversas personalidades deixem de estar unificadas no todo orgânico objectivo que compõe a forma do drama e que cada uma dessas personalidades se torne ela mesma um autor com uma biografia, visão do mundo, modo de sentir, obra e estilo inteiramente autónomos. Assim, a criação da heteronímia pressupõe a existência de um espaço literário que mantenha a substância do drama, mas em que as diversas personalidades que interagem umas com as outras deixem de se confinar à estrutura de uma peça dramática unificada pelo todo orgânico. É neste ponto que se manifesta o reflexo da leitura pessoana de Novalis. A criação de uma personalidade heteronímica, isto é, de uma personalidade com uma biografia, visão do mundo, modo de sentir, obra e estilo inteiramente autónomos tem como condição previa o poder de despertar verdadeiramente em si uma individualidade estranha, de que nos fala Novalis. Lemos nesse sentido a seguinte passagem de um trecho destinado ao texto "Aspectos":

12 Com efeito, lemos na Tábua Bibliográfica de Pessoa as seguintes considerações relativas à constituição do "drama em gente": "As obras heterónymas de Fernando Pessoa são feitas por, até agora, trez nomes de gente - Alberto Caeiro, Ricardo Reis, Alvaro de Campos. Estas individualidades devem ser consideradas como distinctas da do auctor dellas. Fórma cada uma uma espécie de drama; e todas ellas juntas formam outro drama. (...) As obras destes trez poetas formam, como se disse, um conjuncto dramático; e está devidamente estudada a entreacção intellectual das personalidades, assim como as suas próprias relações pessoaes. Tudo isto constará de biographias a fazer, acompanhadas, quando se publiquem, de horoscopos e, talvez, de photographias. É um drama em gente, em vez de em actos." (PESSOA, 1928, p. 10). 
O author humano d'estes livros não conhece em si-proprio personalidade nhenhuma. Quando acaso sente uma personalidade emergir dentro de si, cedo vê que é um ente differente do que elle é, embora parecido; filho mental, talvez, e com qualidades herdadas, mas differenças de ser outrem.

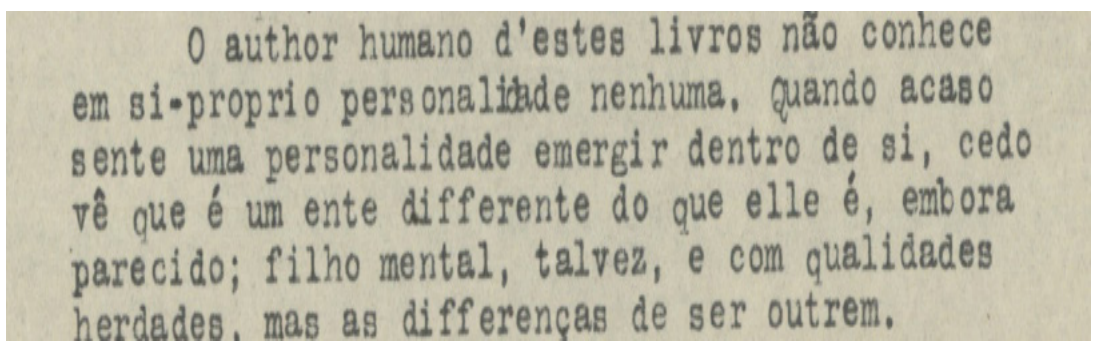

[BNP/E3, $20-70^{\text {r: }}$ detalhe do fac-simile] (PESSOA, 2010a, p. 450)

No entanto, a tradução francesa dos textos de Novalis presente na Biblioteca Particular de Pessoa apresenta-nos outros indícios que nos permitem estabelecer a ligação entre Os fragmentos do autor alemão e a questão da heteronímia em Fernando Pessoa. De entre os diversos fragmentos de Novalis sublinhados por Pessoa encontramos o seguinte texto:

Uma ideia é tão mais sólida, tão mais individual e tão mais entusiasmante quanto maior for o número de pensamentos, de mundos e de estados de alma que nela entrecruzem e toquem.

[Une idée est d'autant plus solide, plus individuelle et plus excitante qu'un plus grand nombre de pensées, de mondes et d'états d'âme s'entrecroisent et se touchent en elle.]

\section{Une idée est d'autant plus solide, plus indivi-} duelle et plus excitante qu'un plus grand nombre de pensées, de mondes et d'états d'âme s'entrecroisent et se touchent en elle.

[CFP, $8-388:$ p. 117 - detalhe do fac-simile]

Este trecho apresenta-nos elementos fundamentais para se compreender a constituição do "drama em gente" pessoano. A criação da pluralidade de personalidades que compõem o "drama em gente" tem como pressuposto o entrecruzar de uma multiplicidade de estados de alma, de mundos e de 
pensamentos personificados através de um conjunto de personalidades com biografias e obras inteiramente autónomas. Este processo de dramatização e de criação de personalidades literárias autónomas é muito anterior à criação dos heterónimos. Com efeito, a primeira aparição pública dos heterónimos ocorre em 1915 com a publicação do "Opiário" e da "Ode Triunfal" no primeiro número da revista Orpheu. Mas a criação de personalidades literárias é muito anterior ao surgimento público dos heterónimos. No espólio de Fernando Pessoa encontramos todo um trabalho pré-heteronímico que viria a ser a base para a posterior constituição dos heterónimos de Pessoa. ${ }^{13}$ Assim, a criação do "drama em gente" conta com todo uma pré-história, que tem sucessivas etapas e que viria a culminar na criação das personalidades heteronímicas. Por exemplo, entre 1902 e 1905 encontramos vários exemplares de um jornal intitulado $\mathbf{O}$ palrador onde Fernando Pessoa faz colaborar personalidades como Dr. Pancrácio, Luís António Congo, Eduardo Lança, Adolph Moscow, Marvell Kisch e Sableton Kay ${ }^{14}$. Num caderno, escrito por volta de 1908, com o título "O livro da transformação ou Livro das tarefas" [The transformation book or Book of tasks] encontramos também a atribuição de diversas tarefas literárias e de cariz sociopolítico a personalidades literárias como Alexander Search, Pantaleão, Jean Seul de Méluret e Charles James Search. (LOPES, 1990, p. 194-97). O palrador e "O livro da transformação" são dois exemplos da forma como é possível acompanhar na pré-heteronímia o entrecruzar de pensamentos, de mundos e de estados de alma que viriam culminar na construção do "drama em gente". A constituição do processo de dramatização e a despersonalização que lhe é implícita são muito anteriores à leitura de Os fragmentos de Novalis. No entanto, Pessoa viria a reconsiderar

13 Para além dos heterónimos Pessoa cria ainda um conjunto de semi-heterónimos e de outras personalidades subalternas que poderão ser classificadas como sub-heterónimos, que viriam igualmente a ser sustentados por todo um trabalho pré-heteronímico. Um semi-heterónimo distingue-se de um heterónimo pela circunstância de que, enquanto o heterónimo tem um estilo diferente do autor real da escrita, o semi-heterónimo tem um estilo semelhante ao autor real da escrita. É isso que Pessoa nos diz a respeito do seu semi-heterónimo Bernardo Soares: “(...) Bernardo Soares, distinguindo-se de mim por suas idéas, seus sentimentos, seus modos de ver e de comprehender, não se distingue de mim pelo estylo de expor. Dou a personalidade differente atravez do estylo que me é natural, não havendo mais que a distincção inevitavel do tom especial que a propria especialidade das emoções necessariamente projecta." [BNP/E3, $\left.16-60^{\mathrm{r}}\right]$. O subheterónimo é, em contrapartida, uma personalidade concebida por Pessoa com o intuito de divulgar e de traduzir para outras línguas das obras dos heterónimos de Pessoa, bem como de outros autores portugueses ou temáticas, na sua maioria, relativas a Portugal, como é, por exemplo, o caso de I. I. Crosse e, pelo menos num certo período da sua produção literária, de Thomas Crosse.

14 Para efeitos de consulta deste jornal ver: Teresa Rita Lopes, Pessoa por conhecer, Lisboa, Editorial Estampa, 1990, vol. II, pp. 134-147; Fernando Pessoa, Cadernos - Tomo I, edição de Jerónimo Pizarro, Lisboa, Imprensa Nacional Casa da Moeda, 2009, pp. 69-78. 
retrospectivamente toda a produção anterior à heteronímia à luz dos conceitos presentes nos fragmentos de Novalis.

Com efeito, num documento sobre a génese da heteronímia, onde Fernando Pessoa apresenta inúmeros aspectos que viria a desenvolver na carta de 13 de Janeiro de 1935 sobre a constituição dos heterónimos, lemos:

Tive sempre, desde criança, a necessidade de aumentar o mundo com personalidades fictícias, sonhos meus rigorosamente construídos, visionados com clareza fotográfica, compreendidos por dentro das suas almas. Não tinha eu mais que cinco anos, e, criança isolada e não desejando senão assim estar, já me acompanhavam algumas figuras de meu sonho um capitão Thibeaut, um Chevalier de Pas - e outros que já me esqueceram, e cujo esquecimento, como a imperfeita lembrança daqueles, é uma das grandes saudades da minha vida.

Isto parece simplesmente aquela imaginação infantil que se entretém com a atribuição de vida a bonecos ou bonecas. Era porém mais: eu não precisava de bonecas para conceber intensamente essas figuras. Claras e visíveis no meu sonho constante, realidades exactamente humanas para mim, qualquer boneco, por irreal, as estragaria. Eram gente.

Além disto, esta tendência não passou com a infância, desenvolveu-se na adolescência, radicou-se com o crescimento dela, tornou-se finalmente a forma natural do meu espírito. Hoje já não tenho personalidade: quanto em mim haja de humano, eu o dividi entre os autores vários de cuja obra tenho sido o executor. Sou hoje o ponto de reunião de uma pequena humanidade só minha.

Trata-se, contudo, simplesmente do temperamento dramático elevado ao máximo; escrevendo, em vez de dramas em actos e acção, dramas em almas. Tão simples é, na sua substância, este fenómeno aparentemente tão confuso. (PESSOA, 1966, P. 101-102)

Este texto, que é um testemunho da importância do trabalho préheteronímico para a constituição dos heterónimos, constitui-se como uma evidência da relevância da leitura de Novalis para a reconsideração da produção anterior à heteronímia, assim como para a teorização do processo de criação dos heterónimos. De acordo com este texto, a construção do espaço literário dramático pessoano pressupõe a criação de um «drama em almas». A criação de um «drama em almas» é resultado, por um lado, do poder de despertar verdadeiramente em si uma individualidade estranha evocado em Os fragmentos de Novalis e, por outro lado, do entrecruzar de pensamentos, de mundos e de estados de alma - igualmente enunciado pelo autor alemão - 
que são separadamente personificados nas diversas individualidades estranhas que são despertadas. Na pré-heteronímia encontramos toda a genealogia da forma como as diversas individualidades estranhas assim como o entrecruzar dos pensamentos e estados de alma se vão configurando nas sucessivas fazes da obra de Pessoa, isto é, dos diversos experimentos literários que Pessoa foi realizando até chegar à construção do «drama em almas» heteronímico e que encontram expressão nos diversos textos teóricos sobre a heteronímia. Novalis fornece, deste modo, os elementos que viriam a constituir o material para a constituição da fundamentação teórica do processo de criação dos heterónimos e para a reconsideração do trabalho pré-heteronímico. Assim, a leitura de Os fragmentos de Novalis desempenha um papel fundamental na sustentação teórica da obra heteronímica e na reavaliação também teórica da pré-heteronímia de Fernando Pessoa.

\begin{abstract}
This article seeks to investigate the relationships between the readings that Fernando Pessoa did of the work of Novalis, the German writer and philosopher, and the problem concerning heteronyms. In fact, Pessoa's private library contains many works of Novalis. A French translated edition of Os discípulos em Saïs is very consulted inlighting various facts about the use of heteronyms in Pessoa's work.

Keywords: Fernando Pessoa. Novalis. Heteronyms. Private Library of Fernando Pessoa. Estate of Fernando Pessoa.
\end{abstract}

Referências

LICHTENBERGER, Henri. Novalis. Paris: Bloud \& C ${ }^{\text {ie }}$ Éditeurs, 1912. [CFP, 8-169].

LOPES, Teresa Rita. Pessoa por conhecer. Lisboa: Editorial Estampa, 1990, vol. II.

MAETERLINCK, Maurice. Monna Vanna. Paris : Librairie Charpentier et Fasquelle, 1913. [CFP, 8-332]

MAETERLINCK, Maurice. Théatre. 3 vols., Bruxelles: Paul Lacomblez, 1908. [CFP, 8-333]

NOVALIS, Friedrich. Les disciples a saïs et Les fragments de novalis (tra- 
duits de l'allemand et precécédés d'une introduction par Maurice Maeterlinck). Bruxelles: Paul Lacomblez, 1914. [CFP, 8-388]

PESSOA, Fernando. Tábua bibliográfica. In Presença, $n^{\circ} 17$, Dezembro de 1928, p.10.

PESSOA, Fernando. Espólio de Fernando Pessoa, Inventário (Biblioteca Nacional de Portugal, Espólio 3). Lisboa: Biblioteca Nacional, 1986.

PESSOA, Fernando. Obra poética e em prosa. vol. II. Porto: Lello \& Irmãos, 1986a.

PESSOA, Fernando. Correspondência (1923-1935). Edição de Manuela Parreira da Silva. Lisboa: Assírio \& Alvim, 1999.

PESSOA, Fernando. Crítica - ensaios, artigos e revistas. Lisboa: Assírio \& Alvim, 2000.

PESSOA, Fernando (António Mora). Obras de António Mora. Edição de Luís Filipe Teixeira. Lisboa: INCM, 2002.

PESSOA, Fernando. Páginas íntimas e de auto-interpretação. Textos estabelecidos e prefaciados por Georg Rudolf Lind e Jacinto do Prado Coelho. Lisboa: Ática, 1966.

PESSOA, Fernando (Álvaro de Campos). Poesia. Edição de Teresa Rita Lopes. Lisboa: Assírio e Alvim, 2002a.

PESSOA, Fernando. Cadernos - Tomo I. Edição de Jerónimo Pizarro, Lisboa: Imprensa Nacional Casa da Moeda, 2009.

PESSOA, Fernando. O marinheiro. Edição de Cláudia Souza. Lisboa: Ática, 2010.

PESSOA, Fernando. Livro do desasocego. Edição de Jerónimo Pizarro. Lisboa: Imprensa Nacional-Casa da Moeda, 2010a.

ROBERTSON, J. G. The literature of Germany. London: Williams \& Northgate, 1913. [CFP, 8-470]. 